\title{
Recurrent arsenic induced cancers over 20 years: a surgeon's nightmare!
}

\author{
S. Maji, I. Ghosh, K. Mukherjee, S.K. Sahu, J. Biswas \\ Department of Surgical Oncology, National cancer Institute, India.
}

Keywords: Arsenic; squamous cell carcinoma; arsenicosis; hyperkeratosis; drinking water

\section{Introdcution}

Arsenic poisoning is a common community health problem plaguing India as well as many other countries worldwide. In India West Bengal, Bihar, Chhattisgarh, Jharkhand, Assam and Manipurhas been the worst sufferers. The ill effects of arsenic is well known to the medical community which primarily can be categorized into nonmalignant and malignant manifestations. The former category includes a wide range of symptoms ranging from generalized weakness, anaemia, fatigue to neurotoxicity, hepatotoxicity or chronic gastrointestinal diseases. Out of all malignancies skin cancer is the commonest and deserves attention. These cancers are often multiple, indolent and often occur after a median latency of two decades. Given their tendency to recur even after wide resection and predilection to affect multiple body parts at the same time, re resection becomes challenging and cosmetically demanding. Treatment of such patients may require multiple surgical interventions and require close surveillance to detect internal cancers, local recurrences or new primaries at the earliest.

\section{Case report}

A 52 years gentleman, a part time worker by profession initially developed an episode of fever, generalized fatigue, cough and cold in the year 2000 .He visited several general physicians over the next one year and was treated conservatively for his complaints. In May 2001 he developed nodular swellings over palms and soles of his foot along with multiple hypopigmented spots over chest (Fig.1, 2\&3).He consulted a dermatologist who diagnosed him with arsenic induced skin lesions.

A sample of the tube well and well water he used to consume was tested and the arsenic content was found to be 0.2280 $\mathrm{mg} /$ litre and $0.1050 \mathrm{mg} /$ litre respectively (normal permissible

Correspondence: S. Maji

E-mail: drsuvendumaji@rediffmail.com

DOI: http://10.4038/sljs.v34i4.8324

The Sri Lanka Journal of Surgery 2016; 34(4): 48-50 level- $0.05 \mathrm{mg} /$ litre).The arsenic content of his hairs and nail was $0.51 \mathrm{micrograms} /$ gram and $0.61 \mathrm{micrograms} /$ gram. Biopsy of the skin lesions initially revealed acrokeratosis verrucaformis. He was asked to follow up at close intervals. However he defaulted in follow up. In December 2012 he presented to us with an ulcerated nodular palm lesion.

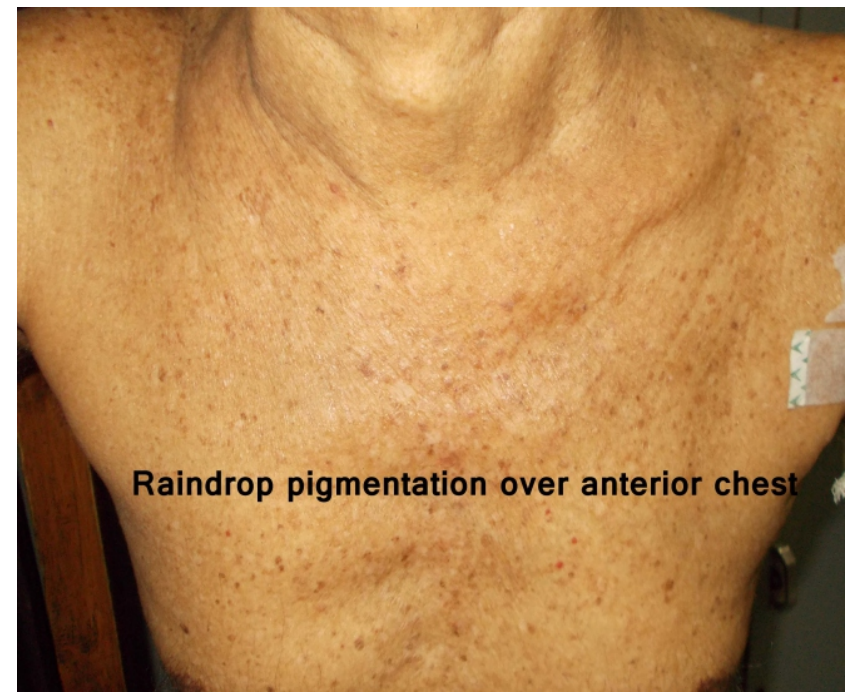

Figure 1. Raindrop pigmentation over anterior chest

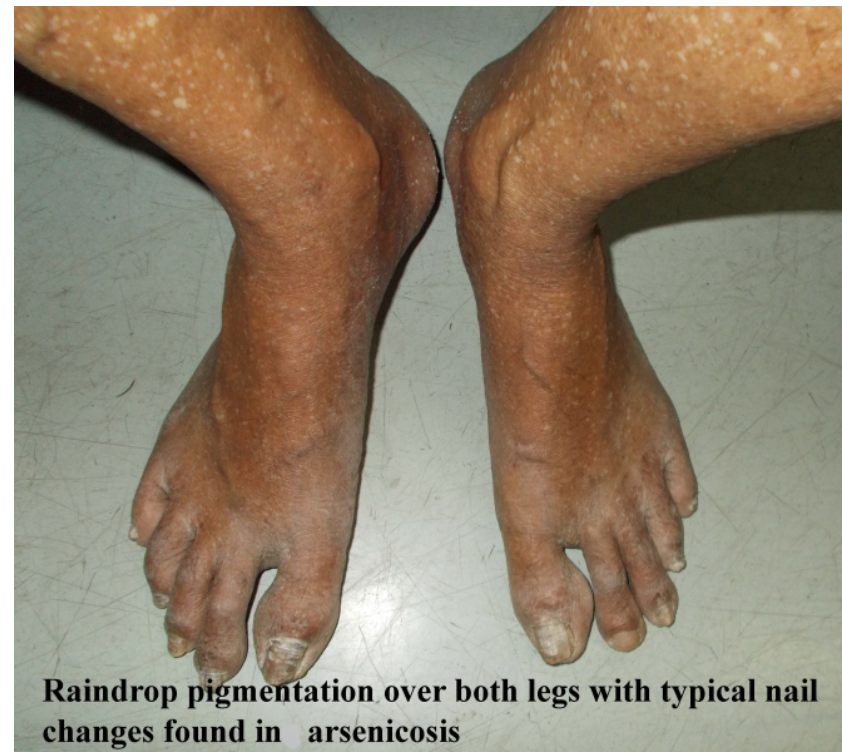

Figure 2. Rain drop pigmentation over both legs with typical nail changes in chronic arsenicosis 


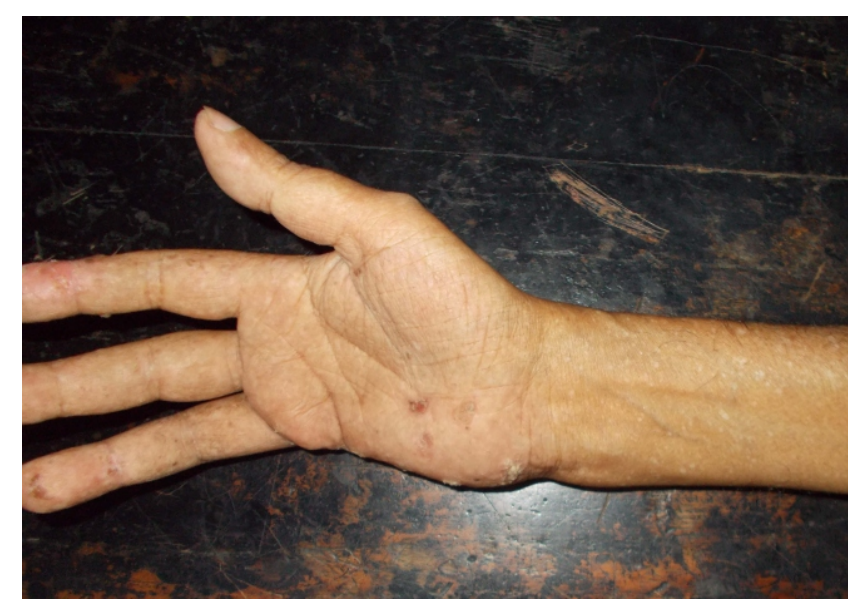

Figure 3. Showing multiple palmar hyperkeratotic nodules-an important cutaneous hallmark of chronic arsenic toxicity

Biopsy from the lesion was reported as well differentiated squamous cell carcinoma (SCC). He underwent below elbow amputation on January 2013. Histopathology showed presence of infiltrating grade 2 SCC. He was discharged and was on intermittent follow up. In 2015 he again presented with a recurrent ulceroproliferative lesion of size $(5 \mathrm{~cm} \times 6$ $\mathrm{cm})$ at the amputated elbow stump.

He underwent disarticulation of left humerus from the left shoulder joint in December 2015. The HPE was grade 3 infiltrating SCC. The resection margins were free. However the shoulder joint was involved and contained sarcomatous elements. The case was discussed in multidisciplinary tumour board and in view of aggressive recurrent disease a decision for forequarter amputation was taken. He was reoperated in February 2016.

The report was high grade squamous cell carcinoma with sarcomatous changes. All margins were free. He was on regular follow up. In April, 2016 he was found to have ulcerative nodular lesion in the palmar aspect of his right little finger. Biopsy was suggestive of moderately differentiated SCC. Wide excision of the lesion was done. The pathology report showed grade 2 squamous cell carcinoma, with negative margins His family members including his wife and son has been educated about the signs, symptoms of arsenic poisoning and has been kept under follow up.

\section{Discussion and conclusions}

Arsenic toxicity is an environmental health hazard prevalent worldwide and in India too. Chronic arsenic toxicity or arsenicosis chiefly occurs when inorganic arsenic contaminates drinking water.

Symptoms are often nonspecific and insidious in onset. However it is interesting to note that few studies ${ }^{1,2,3}$ in the past has shown that even when all members of a family has been exposed to arsenic toxicity, few of them actually gets affected.
The reasons for this enigma still remains unexplained.

The two most important cutaneous markers of chronic arsenicosis are pigmentation and keratosis ${ }^{4}$. The characteristic pigmentation of arsenic poisoning is popularly known as "rain drop" pigmentation which occurs due to presence of multiple roundish hypopigmented macules dispersed against a dark hyperpigmented background.

Pigmentation sometimes may effect mucous membranes like the buccal mucosa or the under surface of tongue. Melanosis, leukodermia or leukomelanosis are other rarer patterns of pigmentation found in arsenicosis ${ }^{4}$. Arsenical hyperkeratosis chiefly occurs on palms and plantar aspect of feet. These lesions may have a nodular or horny appearance.

According to $\mathrm{Yeh}^{5}$, these lesions can be classified into two types: type A (benign) and type B (malignant).Our case had type B lesions. The appearance of these skin manifestations do not have a fixed latency period which vary usually from 6 months to 3 years. Chronic arsenicosis may also present with anaemia, generalized weakness, peripheral neuropathy, interstitial lung disease and peripheral vascular disease. Hence routine hemogram, liver function test, renal function test, stool examination and radiological chest X ray and ECG must be done in all cases. Other investigations like colour doppler of limbs, chest computed tomography (CT) scan, nerve conduction velocity may be required as per the presentation.

The level of arsenic in urine $(>50 \mathrm{mg} / \mathrm{L})$ and its concentration in hair $(>1 \mathrm{mg} / \mathrm{kg})$ and nail $(1.08 \mathrm{mg} / \mathrm{kg})$ further corroborates the diagnosis of arsenic toxicity. The IARC (International Agency For Research On Cancer) considers arsenic as a carcinogen ${ }^{6}$ which is responsible for causing skin, bladder and lung cancer ${ }^{7}$.The exact mode of arsenic carcinogenesis is still unknown. However it is hypothesized that methylation of inorganic arsenic turns on its carcinogenic potential by modulating gene transcriptions as well as via epigenetic mechanism. ${ }^{8,9}$

However many questions still remain unanswered even today. The natural history of arsenicosis is not known to us. Likewise the course of various arsenic induced malignancies remains elusive. The exact characteristics of the various type of skin cancers from the surgical perspective has never been studied before. Consequently we do not have established treatment guidelines and follow up protocol for management of such cancers.

Some case reports states that Arsenic induced Lung and Bladder cancers may be treated as per protocol of general malignancy and may yield similar long term results. However in the era of evidence based medicine such extrapolation would be incorrect. Our case shows that wide local excision which is otherwise the standard treatment for SCC with may 
not always yield negative margins when used for arsenic induced carcinomas. The patient underwent repeated wide local excisions of the multiple skin cancers over a span of ten years.

All the tumours were large ulceroproliferative infiltrating and intermediate to high grade type of SCC and the resected margins in most of them were positive for unknown reasons. One of the specimens showed sarcomatous change which indicates malignant degeneration can occur in the lesions over years. It was a difficult clinical scenario where we had to operate on the same patient on several of his body parts within a short period of two years. Multiple counselling sessions were required to convince him to undergo surgery and motivate him to remain in follow up. Though the surgeries were debilitating, the patient did not have local recurrence at most of the operated sites.

Moreover he did not develop any internal malignancy or any metastasis during this two decades of follow up. The cutaneous lesions remained stable over the follow up period and the patient never had any systemic manifestations of the disease. He had no risk factors like sun exposure, smoking or occupational exposure all of which have been described as predisposing factors ${ }^{10}$. Such patients need regular follow up and intensive surveillance throughout their lifetime for detection of new cancers.

\section{References}

1. Goldsmith S, From AHL (1980). Arsenic - induced Atypical Ventricular Tachycardia, N. Engl. J. Med. 303: 1096-1098 https://doi.org/10.1056/NEJM198011063031905

2. Harrington J. M, Middaugh J. P, Morse D. L \& Housworth J
(1978). A survey of a population exposed to high concentrations of arsenic in well water in Fairbanks, Alaska. Am. J. Epidemiol. 108:377-385.

3. Valentine J.L., Kang H.K., \& Spivey G (1979). Arsenic levels in human blood, urine, and hair in response to exposure via drinking water. Environ. Res. 20:24-32. https://doi.org/10.1016/0013-9351 (79) 90082-3

4. Guha Mazumder DN, Haque R, Ghosh N, De BK, Santra A, Chakraborty D, et al. Arsenic levels in drinking water and the prevalence of skin lesions in West Bengal, India. Int J Epidemiol 1998; 27:871e7

5. Yeh, S. (1973). Skin cancer in chronic arsenicism. Hum Pathol. 4: 469-485. https://doi.org/10.1016/S0046-8177 (73)80060-7

6. IARC. Some drinking - water disinfectants and contaminants, including arsenic. Monographs on the evaluation of carcinogenic risks to humans. Lyon, France: WHO; 2004. 84: 61e96.

7. Naujokas MF, Anderson B, Ahsan H, Aposhian HV, Graziano $\mathrm{JH}$, Thompson $\mathrm{C}$, et al. The broad scope of health effects from chronic arsenic exposure: update on a worldwide public health problem. Environ Health Perspect 2013; 121(3):295-302. https://doi.org/10.1289/ehp.1205875

8. Martinez VD, Vucic EA, Becker-Santos DD, Gil L, Lam WL. Arsenic exposure and the induction of human cancers. J Toxicol 2011;2011:431287 https://doi.org/10.1155/2011/431287

9. Sinha S, Paul R, Khan I, Sarkar M, Manna A, Asifullah Md., Majumdar A. Successful treatment of arsenic-induced lung malignancy: a case report. Int J Med Sci Public Health 2016; 5 (Online First). https://doi.org/10.5455/ijmsph.2016.23012016370

10. Christoforidou EP, Riza E, Kales SN, Hadjistavrou K,Stoltidi M, Kastania AN, et al. Bladder cancer and arsenic through drinking water: a systematic review of epidemiologic evidence. J Environ Sci Health A Tox Hazard Subst Environ

\section{Key Points:}

- Diagnosis of arsenic induced malignancies needs strong clinical suspicion and consideration of the historical background of the case.

- Treatment of arsenic induced squamous cell carcinomas with wide local excision c a yield good long term results

- Patient should be closely followed up and diagnosis of arsenic toxicity should prompt screening of family members too.

- Follow up should be life long as the patients may develop a second malignancy in the long run. 